\title{
Plasma Cholesteryl Sulfate in Friedreich's Ataxia
}

\author{
A.C. Nestruck ${ }^{1}$, Y.S. Huang ${ }^{1}$, K. Eid ${ }^{1}$, R. Dufour ${ }^{1}$, L. Boulet ${ }^{1}$, \\ A. Barbeau ${ }^{2}$ and J. Davignon ${ }^{1}$
}

\begin{abstract}
Alteration of membrane fluidity and anomalies of membrane structural proteins have been suspected in Friedreich's ataxia. Plasma lecithin:cholesterol acyltransferase (LCAT) activity is also lowered in this disease, presumably because of a substrate effect. The membrane-stabilizing effect of cholesteryl sulfate (CS) and its inhibitory effect on LCAT activity prompted us to measure this substance in the plasma of Friedreich's ataxia patients as well as in normal subjects and in patients with Charlevoix-Saguenay disease. Plasma cholesteryl sulfate concentrations were significantly higher in Friedreich's ataxia, with levels above the upper limit of normal in nearly half of the cases. This increase was unrelated to age, sex or plasma cholesterol levels, but closely associated with the severity of the disease and thus considered to be secondary. A similar phenomenon (except the association with severity) was observed in Charlevoix-Saguenay ataxia. Levels also tended to be higher in first-degree relatives of Friedreich cases. The significance of these findings is discussed in the light of recent knowledge and experimental data obtained in this laboratory on rats made deficient in essential fatty acids. The highest concentrations of CS observed in Friedreich's ataxia ( $1097 \mu \mathrm{g} / \mathrm{dL}, 6$ times the normal mean) was only $25 \%$ as high as the concentrations reported to inhibit LCAT activity.
\end{abstract}

RÉSUMÉ: Des altérations de la fluidité membranaire et des anomalies des protéines structurales des membranes ont été soupçonnées dans l'ataxie de Friedreich. L'activité de la lécithine:cholestérol acyltransférase (LCAT) plasmatique est aussi abaissée dans cette maladie présumément à cause d'un effet du substrat. L'effet stabilisateur du cholestéryl sulfate (CS) sur les membranes et sa capacité d'inhiber la LCAT nous ont incités à mesurer cette substance dans le plasma de patients atteints de la maladie de Friedreich, de la maladie de Charlevoix-Saguenay et chez des sujets normaux. Les concentrations plasmatiques de CS étaient significativement plus élevées chez les Friedreich, les niveaux dépassant la limite supérieure de la normale dans près de la moitié des cas. Cette augmentation n'était pas reliée à l'âge, au sexe ou aux niveaux sanguins de cholestérol, mais elle était étroitement associée à la gravité de la maladie et conséquemment considérée comme secondaire. Une tendance semblable (mise à part la relation avec la gravité) a été observée dans le Charlevoix-Saguenay. Les niveaux avaient tendance à être plus élevés aussi chez les parents du premier degré des cas d'Ataxie de Friedreich. Les implications de ces résultats sont discutées à la lumière d'observations récentes et de données expérimentales obtenues dans notre laboratoire sur des rats rendus déficients en acides gras essentiels. Le plus haut niveau de CS plasmatique observé dans un cas d'ataxie de Friedreich ( $1097 \mu \mathrm{g} / \mathrm{dl}, 6$ fois la moyenne des sujets témoins) n'atteignait que $25 \%$ des concentrations requises pour inhiber l'activité de la LCAT.

Can. J. Neurol. Sci. 1984; 11:631-636

Cholesteryl sulfate (CS), which occurs in cell membranes (Bleau et al., 1974), is more hydrophilic than free cholesterol. It has been proposed that the sulfate moiety of CS interacts with basic proteins while the steroid portion of the molecule is engaged in a hydrophobic interaction with other membrane lipids (Bleau et al., 1974). This type of interaction has been reported by Braun and Radin (1969) between cerebroside sulfate and a water-soluble membrane protein isolated from brain myelin. Cholesteryl sulfate is currently considered to be a membrane stabilizer with the ability to reduce the osmotic fragility of red blood cells (Bleau et al., 1974) and to enhance the resistance of sperm membranes to mechanical rupture (Lalumière et al., 1976). This role of cholesteryl sulfate has been invoked in explaining the acrosome reaction which leads to the penetration of the zona pellucida of the ovum by the sperm; sterol sulfatase destabilizes the acrosomal membrane and initiates the capacitation and the fertilization process (Langlais et al., 1981). This desulfation would allow lecithin:cholesterol acyl-transferase (LCAT, EC 2.3.1.43) to react with the free hydroxyl group of cholesterol to produce cholesteryl esters and lysolecithin, both considered to play a role in these processes.

Friedreich's ataxia is a disease where membrane fluidity may be altered (Huang et al., 1980) and where anomalies of membrane structural proteins have been suspected (Butterfield et

From the Departments of Lipid Metabolism and Atherosclerosis Research (1) and Neurobiology (2), Clinical Research Institute of Montreal.

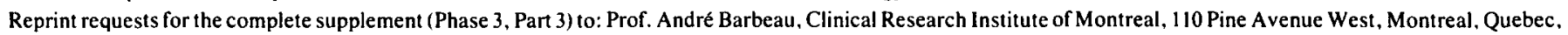
Canada $\mathrm{H} 2 \mathrm{~W} 1 \mathrm{R} 7$ 
Table 1: Mean ( \pm SD) age, plasma cholesterol (CH), triglycerides (TG), cholesteryl sulfate (CS) and CS/CH ratio in normal subjects, ataxic patients and hypercholesterolemic patients.

\begin{tabular}{|c|c|c|c|c|c|}
\hline & $\begin{array}{c}\text { HEALTHY } \\
\text { VOLUNTEERS }\end{array}$ & $\begin{array}{c}\text { FIRST.DEGREE } \\
\text { RELATIVES }\end{array}$ & $\begin{array}{c}\text { FRIEDREICH'S } \\
\text { ATAXIA } \\
\end{array}$ & $\begin{array}{l}\text { CHARLEVOIX- } \\
\text { SAGUENAY }\end{array}$ & $\begin{array}{c}\text { FAMILIAL } \\
\text { HYPER- } \\
\text { CHOLESTEROLEMIA }\end{array}$ \\
\hline Number (males) & $24(12)$ & $10(7)^{*}$ & $42(18)^{*}$ & $8(1)$ & $17(8)$ \\
\hline Number in Stage 1 & 0 & 0 & 1 & 0 & 0 \\
\hline Stage II & 0 & 0 & 9 & 1 & 0 \\
\hline Cholesterol (mg/dL) & $165 \pm 33$ & $166 \pm 35$ & $168 \pm 36$ & $164 \pm 39$ & $367 \pm 77$ \\
\hline Triglycerides (mg/dL) & $74 \pm 33$ & $95 \pm 80$ & $94 \pm 56$ & $101 \pm 38$ & $141 \pm 71$ \\
\hline Cholesteryl-S04 $(\mu \mathrm{g} / \mathrm{dL})$ & $183 \pm 36$ & $210 \pm 48$ & $280 \pm 107^{a}$ & $252 \pm 90^{b}$ & $365 \pm 95^{\mathrm{a}}$ \\
\hline $\mathrm{CS} \times 1000 / \mathrm{CH}$ & $1.12 \pm 0.21$ & $1.31 \pm 0.13$ & $1.72 \pm 0.70^{\mathrm{a}}$ & $1.54 \pm 0.37^{\mathrm{a}}$ & $1.00 \pm 0.22$ \\
\hline
\end{tabular}

\footnotetext{
* One outlier excluded from this group for the calculations of $\mathrm{CS}$ and ratio (see text)

a different from group of healthy volunteers at $p<0.001$

$b$ different from group of healthy volunteers at $p<0.005$
}

al., 1979). It has also been shown that LCAT activity in vitro is impaired in the plasma of Friedreich's patients when both substrate (HDL) and enzyme (d > $1.21 \mathrm{~g} / \mathrm{mL}$ plasma fraction) of the ataxic patients are incubated together but not when the ataxia LCAT enzyme is incubated with control substrate (Huang et al., 1980). Furthermore, $C S$ has been reported to inhibit LCAT activity (Nagakawa and Kojima, 1976). These observations prompted us to study the plasma concentrations of cholesteryl sulfate in Friedreich's ataxia to see if an increase, perhaps compensatory, would be present; a finding that would also raise the hypothesis of a CS-mediated inhibitory effect on LCAT activity and not only a substrate effect as previously proposed.

\section{MATERIALS AND MethodS}

\section{Subjects}

This study was carried out on 42 patients affected with Friedreich's ataxia as defined by the criteria of the QCSFA (Barbeau, 1976). They included 18 males and 24 females between the ages of 9 and 34 years. They were recruited from the Neurobiology clinic at the Clinical Research Institute of Montreal $(n=24,7 \mathrm{M}, 17 \mathrm{~F} ; 24.9 \pm 5.5 \mathrm{yr}, \mathrm{x} \pm \mathrm{SD})$ and from a Pediatric Neurology clinic at Ste-Justine Hospital $(n=18,11$ M, 7 F; $16.5 \pm 3.8 \mathrm{yr}$ ) in Montreal. Ten unaffected first-degree relatives of the second group ( $5 \mathrm{M}, 5 \mathrm{~F}$ ), 24 healthy volunteers (12 M, $12 \mathrm{~F}$ ) from the personnel of the Institute and their relatives and 17 subjects $(8 \mathrm{M}, 9 \mathrm{~F})$ with heterozygous familial hypercholesterolemia were used for comparison. Samples were also obtained from eight patients $(1 \mathrm{M}, 7 \mathrm{~F})$ with CharlevoixSaguenay disease, a recessive form of spastic ataxia (Bouchard et al., 1978). Functional staging of the ataxia was done according to the criteria of Pourcher and Barbeau (1980). Twenty subjects in the Friedreich's ataxia group were related. There were 6 pairs of siblings among the cases from the Neurobiology clinic and 4 among the patients from Ste-Justine Hospital. There were two sibs in the Charlevoix-Saguenay group. Heterozygous familial hypercholesterolemia was defined by the criteria of Fredrickson et al., (1978). All subjects with this disease had a low density lipoprotein cholesterol (LDL-C) greater than $190 \mathrm{mg} / \mathrm{dL}, 10$ had a triglyceride/cholesterol ratio $<0.40$ (type IIa) and 7 had a ratio $\geqslant 0.40$ (type IIb), nine out of $17 \mathrm{had}$ tendon xanthomas and none were related. Age and sex distribution as well as plasma lipid levels are given in Table 1.

\section{Methods}

Venous blood was drawn in the morning after a 12-to 13-hour fast into tubes containing disodium EDTA $(1 \mathrm{mg}$ per $\mathrm{mL}$ of blood) and the plasma was spun (2500 rpm $15 \mathrm{~min})$ and kept in the cold until processed. Plasma total cholesterol (Allain et al., 1974) and triglycerides (Sampson et al., 1975) were measured enzymatically with an autoanalyzer (ABA-100, Abbott Laboratories, Pasadena, CA). Plasma cholesteryl sulfate was determined by gas liquid chromatography with a method developed in our laboratory using $\beta$-sitosteryl sulfate as an internal standard (Huang et al., 1981).

\section{Results}

The most striking finding was the presence of higher mean plasma cholesteryl sulfate concentrations in the Friedreich and the Charlevoix-Saguenay groups than in the group of healthy volunteers (Table 1). This occurred in spite of the fact that all 3 groups had the same mean plasma cholesterol concentration. There was no segregation of the high concentrations according to sex (Figure 1) and CS levels were not correlated with age ( $r$ $=0.166)$. On the other hand, the higher concentrations were related to the stage of the diseases: the mean plasma CS was 189 $\pm 49 \mu \mathrm{g} / \mathrm{dL}$ for combined stages $\mathrm{I}$ and $\mathrm{II}(\mathrm{n}=10)$ and $302 \pm$ $104 \mu \mathrm{g} / \mathrm{dL}$ for stages III and IV combined $(\mathrm{n}=31)(\mathrm{p}<0.001)$. The CS concentrations did not differ significantly between stages III and IV, the values being respectively $309 \pm 134$ $(n=11)$ and $298 \pm 87(n=20)$. As expected, patients at stages I and II were significantly younger ( $15.9 \pm 2.6 \mathrm{yr})$ than those at stages IIl and IV $(23.1 \pm 5.7, \mathrm{p}<0.001)$. However, there were 9 subjects younger than 20 years of age in the latter group with a mean age of $16.2 \pm 1.8$ and $C S$ of $316 \pm 101$ and again $C S$ was not correlated with age in the total sample. There were not enough subjects in the Charlevoix-Saguenay group with mild disease to make a comparison of CS levels with staging of 


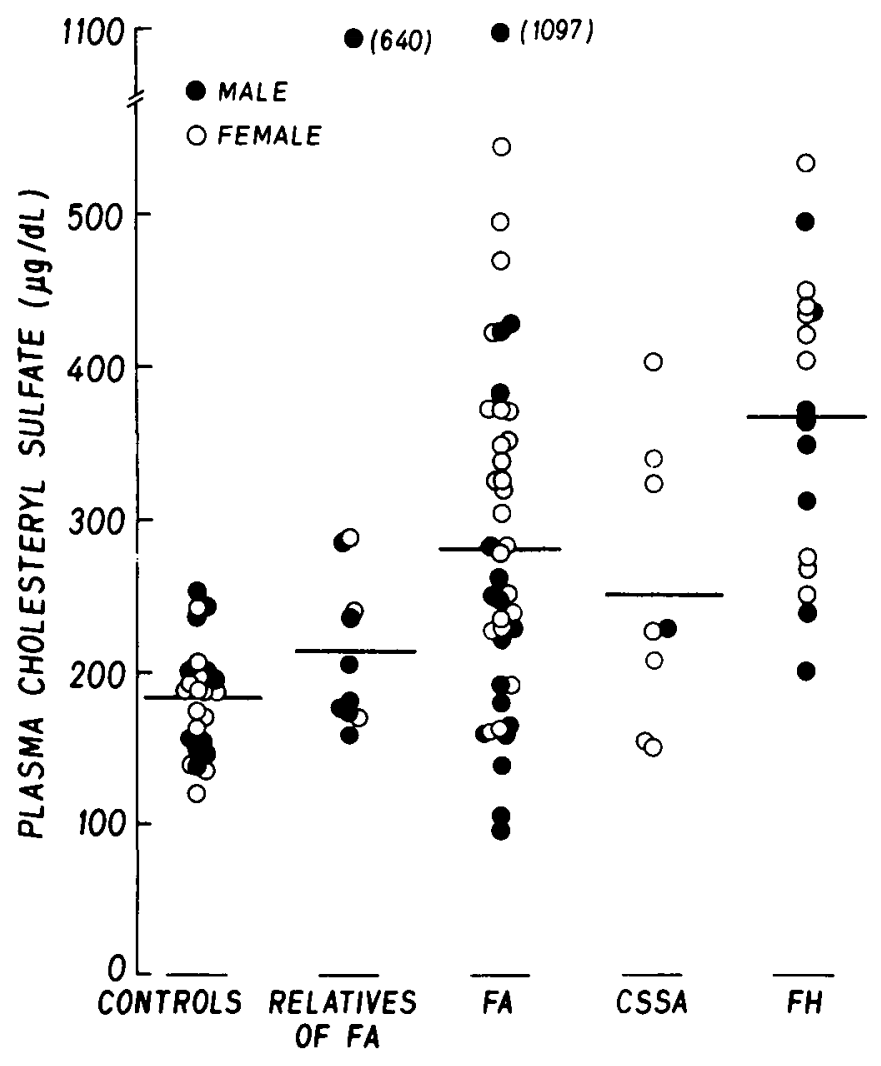

Figure 1 - Plasma cholesteryl sulfate levels incontrols, first-degree relatives of subjects with Friedreich's ataxia, Friedreich's ataxia (FA) patients, Charlevoix-Saguenay (CSSA) disease and heterozygous familial hypercholesterolemia $(F H)$. Cholesteryl sulfate is significantly higher than in controls for FA (p 0.001): CSSA ( $p 0.005)$ and FH ( $p 0.001)$. The mean values for the relatives and for the FA group were calculated with the exclusion of one outlier in each group.

ataxia. There was one outlier with a CS of $640 \mu \mathrm{g} / \mathrm{dL}$ in the group of first-degree relatives and one with $1097 \mu \mathrm{g} / \mathrm{dL}$ in the Friedreich group (Figure 1). These were not used for the calculations of the means in Table 1. When the Friedreich outlier was included, it increased the variance for this group (CS $=299 \pm$ $165, \mathrm{CS} \times 1000 / \mathrm{CH}=1.86 \pm 1.12, \mathrm{n}=42$ ) but only slightly affected the level of significance for the contrast with the group of normal volunteers $(p<0.005$ instead of $p<0.001)$. There was one subject with mild hyperlipidemia in the group of healthy volunteers, his cholesterol and triglycerides being respectively 258 and $109 \mathrm{mg} / \mathrm{dL}$ with a CS level of $242 \mu \mathrm{g} / \mathrm{dL}$.

Interestingly, half of the subjects with ataxia had plasma concentrations of CS which exceeded the upper limit of normal, set at 2 standard deviations above the mean of the healthy volunteers $(255 \mu \mathrm{g} / \mathrm{dL})$. This is well illustrated in Figure 2 where the frequency distribution of the control group is contrasted with that of the Friedreich's group. This distribution suggests the presence of bimodality in the sample of Friedreich's patients. An analysis of bimodality (Day, 1969) gave estimates of $224 \pm$ 70 and $394 \pm 70 \mu \mathrm{g} / \mathrm{dL}$ of CS for the first and second modes, respectively. The chi-square measure of improvement of fit of these data to two distributions compared to a single distribution was not statistically significant $\left(\chi^{2}=2.84,2\right.$ d.f.). Although this analysis is suggestive of bimodality, the power of the test is low with so few observations.

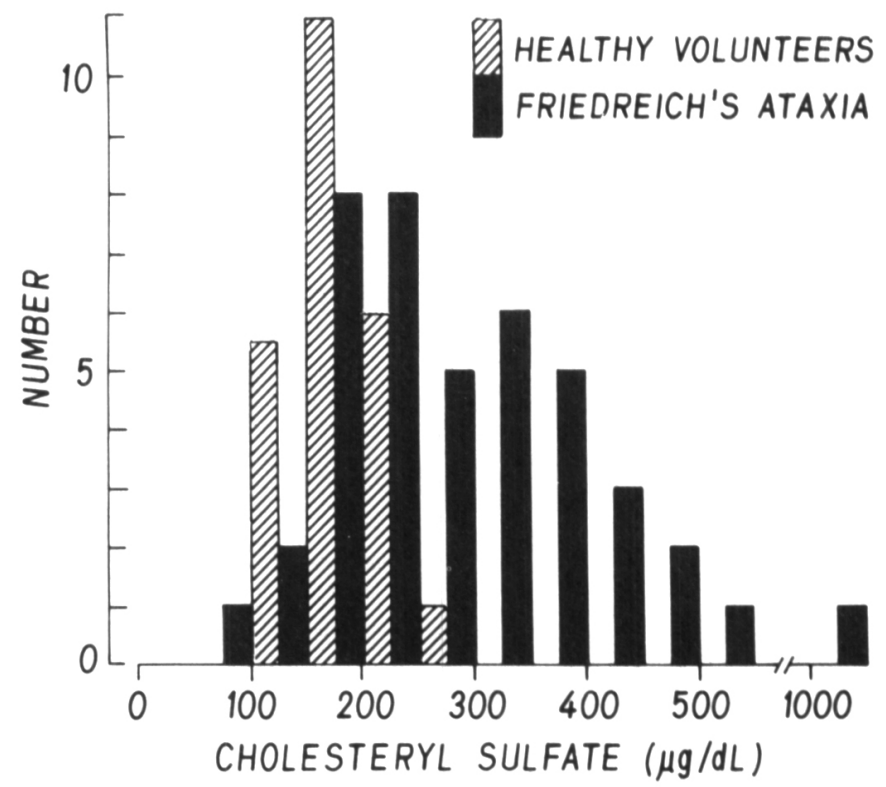

Figure 2 - Frequency distribution of plasma cholesteryl sulfate levels in healthy volunteers and in patients with Friedreich's ataxia. Although the distribution is suggestive of bimodality, the $\mathrm{X}^{2}$ for a two-mode distribution is not statistically significant.

The concentrations of CS observed in the right portion of the distribution are similar to the high levels observed in familial hypercholesterolemia (type IIa) (Table 1 and Figure 3) (Eid et al., 1980). In the Friedreich group, these levels occur in the absence of any elevation of plasma cholesterol so that the ratio CS $x 1000 /$ cholesterol is significantly greater than that of either the control subjects or the hypercholesterolemic patients (Table 1). CS is multiplied by 1000 in this ratio to simplify the handling of the numbers since the concentration of CS in plasma $(\mu \mathrm{g} / \mathrm{dL})$ is 1000 times smaller than that of cholesterol $(\mathrm{mg} / \mathrm{dL})$. Cholesterol and cholesteryl sulfate are significantly and positively correlated in the normal volunteers $(r=0.581, p<0.001)$ and in the hypercholesterolemic subjects $(r=0.675, p<0.005)$ but not in the Friedreich group. The correlation between plasma cholesterol and CS is very close for the combined normolipidemic and hyperlipidemic subjects and the regression line is quite different from that obtained for the Friedreich patients, which lies almost parallel to the CS abscissa (Figure 3). This dissociation of the normal relationship between $\mathrm{CS}$ and $\mathrm{CH}$ further enhanced the difference between the Friedreich cases and the normal volunteers and hyperlipidemic subjects combined. Furthermore, there was evidence of bimodality within the Friedreich sample when a bimodality analysis was performed on the distribution of the ratio of cholesteryl sulfate to cholesterol. The estimate of this ratio was $1.436 \pm 0.797$ for the first mode and $2.808 \pm 0.203$ for the second mode. The contrast between a two-mode distribution and a one-mode distribution was statistically significant for this ratio $\left(x^{2}=7.49,2\right.$ d.f., $\left.p=0.025\right)$.

\section{Discussion}

This is the first report of abnormally high plasma cholesteryl sulfate concentrations in Friedreich's ataxia. Half of the cases had levels above the upper limit of normal, which was set at 2 S.D. above the mean of a control group of 24 healthy volunteers 


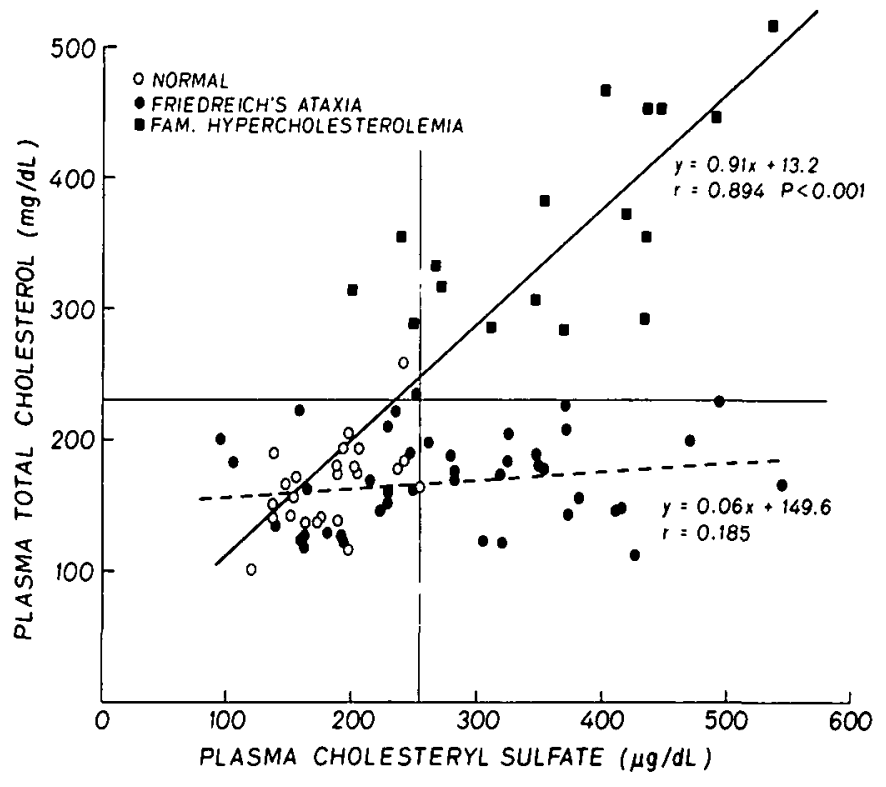

Figure 3-Correlation between plasma cholesterol and plasma cholesteryl sulfate concentrations in normal volunteers, Friedreich's ataxia patients and in cases of familial hypercholesterolemia. The horizontal and the vertical lines are drawn at 2 standard deviations above the mean cholesterol and cholesteryl sulfate concentrations of the control group at $231 \mathrm{mg} / \mathrm{dL}$ and $255 \mathrm{mg} / \mathrm{dL}$ respectively.

( $255 \mu \mathrm{g} / \mathrm{dL})$. The concentrations obtained in this subgroup (364 $\pm 75 \mu \mathrm{g} / \mathrm{dL}, \mathrm{n}=21$ ) were the same as those observed in the cases of familial hypercholesterolemia $(365 \pm 95 \mu \mathrm{g} / \mathrm{dL}, \mathbf{n}=17)$ where high levels have previously been reported (Eid, 1980; Huang et al., 1981). Although one subject with Friedreich's ataxia had a CS value as high as $1097 \mu \mathrm{g} / \mathrm{dL}$, none reached the concentrations observed in recessive $X$-linked ichthyosis $(2000$ to $4000 \mu \mathrm{g} / \mathrm{dL}$ ) (Epstein et al., 1981; Bergner and Shapiro, 1981) which is associated with an absence of cellular steroid sulfatase (Epstein and Leventhal, 1981). To our knowledge, the only other neurological disease where abnormalities of cholesteryl sulfate have been reported is metachromatic leucodystrophy with multiple sulfatase deficiency (Eto et al., 1980). In this disabling condition which combines severe neurological symptoms, gargoyle-like facies, mild hepatosplenomegaly, ichthyosis and skeletal abnormalities, there is an intracellular accumulation of CS and a deficiency of at least seven different enzymes. Plasma cholesteryl sulfate levels have not yet been reported in this disorder.

Plasma CS was not correlated with age and the high concentrations did not segregate according to sex. On the other hand, the CS levels were strongly influenced by the severity of the disease. Patients with stage I (minimal signs, $\mathrm{n}=1$ ) and stage II (mild symptoms, patient capable of leading an independent life, $\mathbf{n}=9$ ) had a mean CS concentration which was very close to that of the normal volunteers. In contrast, those with full-blown symptoms, needing help to move about and transfer (stage III) and patients confined to a wheelchair (stage IV) had significantly higher concentrations $(p<0.001)$. It is difficult to ascertain the meaning of this relationship, which indicates that CS abnormalities are probably not etiologically related to the disease but rather a consequence of it.

In view of the stabilizing effect of cholesteryl sulfate on cell membranes (Bleau et al., 1974; Lalumière et al., 1976), a com- pensatory mechanism could be imagined whereby circulating levels of CS are increased to minimize the adverse effects of membrane changes occurring in Friedreich's ataxia (Butterfield et al., 1979; Huang et al., 1980). If this were the case, it would not be through a general increase in cholesterol synthesis but rather by a selective increase in sulfurylation of cholesterol, perhaps by an inhibition of sterol sulfate sulfohydrolase (EC 3.1.6.2) (France, 1979), or by a stimulation of steroid sulfotransferase activity (Banerjee et al., 1967). In hypercholesterolemia, there is a close relationship between cholesterol levels and cholesteryl sulfate concentrations in plasma (Figure 3). Presumably, as the level of cholesterol rises, more of it is sulfated. In addition, precursors of cholesterol are also sulfated in situations where liver synthesis of cholesterol is known to be increased, as in partial ileal bypass surgery (Massé et al., 1982). In Friedreich's ataxia, the high levels of plasma CS occur in the absence of any elevation in plasma total cholesterol (Figure 3). It is hence another condition like recessive X-linked ichthyosis (Bergner and Shapiro, 1981), where the rise in CS is dissociated from an increase in cholesterol levels, in contrast to hyperlipidemia (Eid, 1980) and pregnancy (Wade, 1970) where both move in the same direction. This dissociation accounts for a significant bimodality of the $\mathrm{CS} \times 1000 / \mathrm{CH}$ ratio within the Friedreich sample.

Since there is a selective and relative deficiency of linoleic acid in Friedreich's ataxia which could presumably alter membrane fluidity, we tested whether a compensatory increase in CS would occur in experimental essential fatty acid (EFA) deficiency. Plasma CS was determined in rats fed an EFAdeficient diet for 12 weeks and in rats where the EFA deficiency was abolished by daily injections of pure methyl linoleate (18:2 $\omega 6$, $200 \mu \mathrm{L}$ i.p.) without replacement of linolenate (18:3w3). Cardiac mitochondria were isolated according to the method of Dow-Walsh et al. (1975), and cholesterol and phospholipid content were determined. The lipid phosphorus content (Bartlett, 1959) of the various phospholipid fractions (including cardiolipin), separated by thin layer chromatography (Skipski et al., 1964), was also determined. Details of the experimental design, methodology and effects on red blood cell osmotic fragility and

Table 2: Plasma cholesteryl sulfate (CS), and cholesterol, phospholipids and phospholipid fractions of rat heart mitochondria from EFAdeficient rats and methyl linoleate-treated EFA-deficient rat.

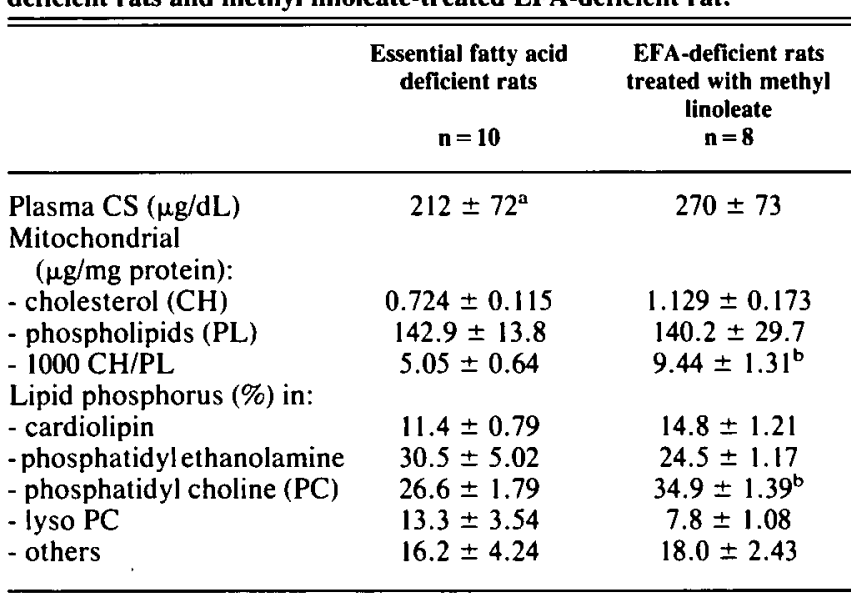

a mean $\pm S . D$.

b differs from EFA-deficient group at $\mathrm{p}<0.01$ 
Table 3: Percent distribution of fatty acids in two phospholipid fractions of heart mitochondria from EFA-deficient rats and methyl linoleatetreated EFA-deficient rats.

\begin{tabular}{cccccc}
\hline \hline & \multicolumn{2}{c}{ CARDIOLIPIN } & & \multicolumn{2}{c}{$\begin{array}{c}\text { PHOSPHATIDYL- } \\
\text { ETHANOLAMINE }\end{array}$} \\
\cline { 2 - 3 } \cline { 5 - 6 } Fatty acid & EFA-deficient & Treated & & EFA-deficient & Treated \\
\hline $16: 0$ & 2.2 & 1.1 & 10.2 & $17.4^{*}$ \\
$16: 1$ & 19.2 & $3.1^{*}$ & & 0.4 & 0.0 \\
$18: 0$ & 2.7 & $1.6^{*}$ & & 32.4 & 29.9 \\
$18: 1$ & 53.8 & $11.0^{*}$ & & 15.0 & $10.7^{*}$ \\
$18: 2$ & 10.4 & $78.1^{*}$ & & 0.00 & $3.5^{*}$ \\
$20: 3$ & 7.5 & $0.8^{*}$ & & 31.0 & $0.5^{*}$ \\
$20: 4$ & 3.5 & 2.3 & & 11.6 & $26.6^{*}$ \\
$22: 4$ & 0.0 & 0.1 & 0.0 & $5.3^{*}$ \\
$20: 3 \omega 9$ & 2.62 & $0.33^{*}$ & 2.95 & $0.0^{*}$ \\
\hline $20: 4 \omega 6$ & & & & \\
\hline
\end{tabular}

* Significantly different from EFA-deficient group at $p<0.001$

membrane composition are published elsewhere (Huang et al., 1983). The results on CS and mitochondrial lipids are presented in Table 2. The plasma CS concentrations were not significantly different between the two groups. The cholesterol/ phospholipid ratio and the percentage of phosphatidylcholine were significantly reduced in the mitochondria of EFA-deficient rats. That severe EFA deficiency was achieved is illustrated in Table 3, where the fatty acid profile (Huang et al., 1983) of the major phospholipid classes (cardiolipin plus phosphatidylethanolamine) is given. The severe depletion of 18:2w6 and the reversal of the triene: tetraene ratio is typical of EFA deficiency in this experimental model. It is thus unlikely that a compensatory increase in plasma CS could be a consequence of the relative 18:2 $\omega 6$ deficiency observed in Friedreich's ataxia (Huang et al., 1978).

An alternative explanation could be that the rise in CS is the result of an accelerated membrane destruction and release of the membrane-associated CS into the circulation. In brain, CS is concentrated in the fraction that is rich in nerve endings (Iwamori et al., 1976) and CS deposition in brain is most rapid in the first few days of life. This corresponds to an increased activity of brain sulfotransferase and the rapid formation of synaptic junctions (Iwamori et al., 1976). CS is also present in myelin, where it is presumed to play a role at an early stage of myelinisation (Bleau et al., 1974). No deficit in these processes has yet been reported in Friedreich's ataxia. CS accumulation in the cells of patients with metachromatic leucodystrophy is thought to contribute to the progressive destruction of myelin and to the neurologic deficit. More studies are needed to determine whether an intracellular accumulation precedes the rise in plasma levels and whether there is any link between myelin, muscle damage and cholesteryl sulfate abnormality in Friedreich's ataxia.

Since there is a suggestion of bimodality for the frequency distribution of cholesteryl sulfate and significant bimodality of the $\mathrm{CS} \times 1000 / \mathrm{CH}$ ratio in Friedreich's ataxia, the possibility remains that previous descriptions of bimodality for several different parameters (Blache et al., 1982; Hamel et al., 1978; Barbeau et al., 1976) could be a reflection of differences in the severity of the disease, several enzyme systems being impaired with progression of the illness.
The hypothesis that an inhibitory effect of CS on LCAT could account for the reduced activity of this enzyme in Friedreich's ataxia (Huang et al., 1980) is unlikely. The effect reported by Nakagawa and Kojima (1976) occurred at concentrations exceeding $10^{-4}$ mole/ $\mathrm{L}$, which correspond to $\mathrm{CS}$ levels of $4820 \mu \mathrm{g} / \mathrm{dL}$ or more; far above the concentrations observed in the Friedreich's patients. The possibility is not however excluded that such inhibition could have contributed in part to the effect observed.

\section{ACKNOWLEDGEMENTS}

This study was supported by grants from the "Association Canadienne de l'Ataxie de Friedreich", the Medical Research Council of Canada (MT-5427) and the Quebec Heart Foundation. The collaboration of Dr. Charles F. Sing from the Department of Human Genetics of the University of Michigan, who tested the CS data for bimodality, is greatly appreciated. We are grateful to Dr. Serge Melançon, Ste-Justine Hospital for providing us with samples of plasma from his patients. The authors wish to thank Ms. Suzanne Paris R.N. for her help with the patients, Mr. Michel Tremblay for technical assistance and Mrs. Réjeanne Ouellet for typing the manuscript. The editorial help and advice of Drs. F. Peter Woodford and Kenneth Roberts is also gratefully acknowledged.

\section{REFERENCES}

Allain CC, Poon LS, Chan FCS, Richmond W, Fu PC (1974) Enzymatic determination of total serum cholesterol. Clin Chem 20: 470-475.

Banerjee RK, Roy AB (1967) The formation of cholesteryl sulphate by androstenolone sulphotransferase. Biochim Biophys Acta 137:211-213.

Barbeau A (1976) Friedreich's ataxia 1976. An overview. Can J Neurol Sci 3: 389-397.

Barbeau A, Butterworth RF, Ngo T, Breton G, Melançon S, Shapcott D, Geoffroy G, Lemieux B (1976) Pyruvate metabolism in Friedreich's ataxia. Can J Neurol Sci 3: 379-388.

Bartlett GR (1959) Phosphorus assay in column chromatography. J Biol Chem 234: 466-468.

Bergner EA, Shapiro LJ (1981) Increased cholesterol sulfate in plasma and red blood cell membranes of steroid sulfatase deficient patients. J Clin Endocrinol Metab 53: 221-223.

Blache D, Bouthillier D, Barbeau A, Davignon J (1982) Plasma lipoprotein lipase and hepatic lipase activities in Friedreich's ataxia. Can J Neurol Sci 9: 191-194.

Bleau G, Bodley FH, Longpré J, Chapdelaine A, Roberts KD (1974) Cholesterol sulfate. I- Occurrence and possible biological function as an amphipathic lipid in the membrane of the human erythrocyte. Biochim Biophys Acta 352: 1-9.

Bouchard JP, Barbeau A, Bouchard R, Bouchard RW (1978) Autosomal recessive spastic ataxia of Charlevoix-Saguenay. Can J Neurol Sci 5: 61-69.

Braun PE, Radin NS (1969) Interactions of lipids with a membrane structural protein from myelin. Biochemistry 8: 4310-4318.

Butterfield DA, Leung PK, Markesbery WR, Barbeau A (1979) Evidence for an altered physical state of membrane proteins in erythrocytes in Friedreich's ataxia. Can J Neurol Sci 6: 295-298.

Day NE (1969) Estimating the components of a mixture of normal distributions. Biometrika 56: 463-479.

Dow-Walsh DS, Mahadevan S, Kramer JKG, Saver FD (1975) Failure of dietary erucic acid to impair oxidation capacity or ATP production of rat heart mitochondria isolated under controlled conditions. Biochim Biophys Acta 396: 125-132.

Eid K (1981) Nouvelle approche d'isolement et de mesure du cholestéryl sulfate (CS) dans le plasma humain. Thesis for M.Sc. in Clinical Sciences, Faculty of Graduate Studies, University of Montreal.

Epstein EH, Leventhal ME (1981) Steroid sulfatase of human leukocytes and epidermis and the diagnosis of recessive $\mathrm{X}$-linked ichthyosis. J Clin Invest 67: 1257-1262.

Epstein EH, Krauss RM, Shackleton CHL (1981) X-linked ichthyosis: increased blood cholesterol sulfate and electrophoretic mobility of low density lipoprotein. Science 214: 659-660. 
Eto Y, Numaguchi S, Tahara T, Rennert OM (1980) Multiple sulfatase deficiency (mucosulfatidosis): impaired degradation of labelled sulfated compounds in cultured skin fibroblasts in vivo. Eur J Pediatr 135: 85-89.

France JT (1979) Steroid sulfatase deficiency. J Ster Biochem 11: 647-651.

Fredrickson DS, Goldstein JL, Brown MS (1978) The familial hyperlipoproteinemias. In: The metabolic basis of inherited disease. JB Stanbury, JB Wyngaarden and DS Fredrickson (eds). McGrawHill, New York, pp. 604-655.

Hamel E, Bédard D, Laviolette F, Butterworth RF, Barbeau A (1978) Familial hyperbilirubinemia in Friedreich's ataxia. Can J Neurol Sci 5: 101-104.

Huang YS, Nestruck AC, Barbeau A, Bouchard JP, Davignon J (1978) Plasma lipids and lipoproteins in Friedreich's ataxia and familial spastic ataxia - evidence for an abnormal composition of high density lipoproteins. Can J Neurol Sci 5: 149-156.

Huang YS, Marcel YL, Vezina C, Barbeau A, Davignon J (1980) Lecithin-cholesterol acyltransferase activity and fatty acid composition of erythrocyte phospholipids in Friedreich's ataxia. Can J Neurol Sci 7: 429-434.

Huang YS, Eid K, Davignon J (1981) Cholesteryl sulfate: measurement with B-sitosteryl sulphate as an internal standard. Can J Biochem 59: 602-605.

Huang YS, Dufour R, Davignon J (1983) Effect of methyl linoleate administration on phospholipid fatty acid composition and osmotic fragility of erythrocytes in essential fatty acid deficient rats. J Amer Coll Nutr 2: 55-61.

Iwamori M, Moser H, Kishimoto Y (1976) Cholesterol sulfate in rat tissues. Tissue distribution, developmental change and brain subcellular localization. Biochem Biophys Acta 441: 268-279.

Lalumière G, Bleau G, Chapdelaine A, Roberts KD (1976) Cholesteryl sulfate and sterol sulfatase in the human reproductive tract. Steroids 27: $247-260$.

Langlais J, Zollinger M, Plante L, Chapdelaine A, Bleau G, Roberts KD (1981) Localization of cholesteryl sulfate in human spermatozoa in support of a hypothesis for the mechanism of capacitation. Proc Natl Acad Sci USA 78: 7266-7270.

Massé R, Huang YS, Eid K, Laliberté C, Davignon J (1982) Plasma methyl sterol sulfates in familial hypercholesterolemia after partial ileal bypass. Can J Biochem 60: 556-563.

Nagakawa M, Kojima S (1976) Effect of cholesterol sulfate and sodium dodecyl sulfate on lecithin:cholesterol acyltransferase in human plasma. J Biochem 80: 729-733.

Pourcher E, Barbeau A (1980) Field testing of an ataxia scoring and staging system. Can J Neurol Sci 7: 339-344.

Sampson EJ, Demers LM, Krieg AF (1975) Faster enzymatic procedure for serum triglycerides. Clin Chem 21: 1983-1985.

Skipski VP, Peterson RF, Barclay M (1964) Quantitative analysis of phospholipids by thin-layer chromatography. Biochem J 90: 374-378.

Wade AP (1970) The estimation of cholesterol sulfate and cholesterol glucuronide in plasma. Clin Chim Acta 27: 109-116. 